\title{
Endoscopic treatment of chronic pancreatitis
}

\author{
Laurent Heyries, Jose Sahel
}

\author{
Laurent Heyries, Jose Sahel, Hôpital de la Conception, 147 Bd \\ Baille, Marseille 13005, France \\ Correspondence to: Jose Sahel, Service de Gastroentérologie, \\ Hôpital de la Conception, 147 Bd Baille, Marseille 13005, \\ France. jose.sahel@ap-hm.fr \\ Telephone: +33-4-91384021 Fax: +33-4-91752304 \\ Received: July 3, 2007 Revised: August 28, 2007
}

\begin{abstract}
Treatment of chronic pancreatitis has been exclusively surgical for a long time. Recently, endoscopic therapy has become widely used as a primary therapeutic option. Initially performed for drainage of pancreatic cysts and pseudocysts, endoscopic treatments were adapted to biliary and pancreatic ducts stenosis. Pancreatic sphincterotomy which allows access to pancreatic ducts was firstly reported. Secondly, endoscopic methods of stenting, dilatation, and stones extraction of the bile ducts were applied to pancreatic ducts. Nevertheless, new improvements were necessary: failures of pancreatic stone extraction justified the development of extra-corporeal shock wave lithotripsy; dilatation of pancreatic stenosis was improved by forage with a new device; moreover endosonography allowed guidance for celiac block, gastro-cystostomy, duodeno-cystostomy and pancreatico-gastrostomy. Although endoscopic treatments are more and more frequently accepted, indications are still debated.
\end{abstract}

(C) 2007 WJG. All rights reserved.

Key words: Chronic pancreatitis; Endoscopic treatment

Heyries L, Sahel J. Endoscopic treatment of chronic pancreatitis. World J Gastroenterol 2007; 13(46): 6127-6133

http://www.wjgnet.com/1007-9327/13/6127.asp

\section{METHODS}

Endoscopic treatment needs a team (operator, anaesthesiologist) aware with Endoscopic Retrograde Cholangiopancreatography (ERCP) procedures. Specific material is necessary: good fluoroscopy with the possibility to magnify pictures, and a duodenoscope with a 4.2 channel allowing insertion of high calibre stent $(10 \mathrm{Fr})$. Moreover, a wide variety of endoscopic ancillary instruments is essential: metallic and hydrophilic guidewire, sphincterotomes, Dormia basket, balloon dilatators and bougie dilatators (5-11.5 Fr), but also very thin guide wire (0.025 inches), fine-tipped sphincterotomes, Soehendra extractors ( $\mathrm{cf}$ infra) ${ }^{[1]}$. Impaction of stones in pancreatic ducts needs the use of extracorporeal shock wave lithotripsy before endoscopic stone extraction ${ }^{[2]}$. Endoscopic treatment also needs naso-pancreatic drains and pancreatic stents that are either polyethylene or Teflon. The choice of length, pattern or external calibre of the stent is decided according to the anatomy of pancreatic ducts. Usually, straight stents with proximal and distal external flaps (to avoid internal or external migration), are used. Other stents like single or double pig-tail stents can be used also.

\section{Endoscopic pancreatic sphincterotomy (PS)}

Firstly described by Fuji ${ }^{[3]}$, PS is generally performed as the first step in order to improve access to the pancreatic duct. A short (5-6 mm) sphincterotomy is oriented at $13 \mathrm{~h}$ with a pure section cutting. Narrowness of pancreatic ducts has justified using special device (thin 0.025 guidewire, fine-tipped sphincterotome). Biliary sphincterotomy, which was firstly recommended before PS, seems not to be systematically performed because, contrary to the firstly experience, PS alone is not associated with a secondary biliary stenosis ${ }^{[4]}$.

Complications of PS occur in $4.2 \%-12.6 \%$ of $\operatorname{cases}^{[4,5]}$. The morbidity rate also depends on other endoscopic procedures done at the same time such as pancreatic stenting or stricture dilatation. It also depends on the inclusion of patients presenting with recurrent attacks of pancreatitis secondary to sphincter of Oddi dysfunction. In this case, morbidity rate is higher, reaching $12.5 \%{ }^{[6]}$. PS is probably no more or no less harmful than a biliary sphincterotomy which is associated with a morbidity rate of $5.4 \%-9.8 \%$ of cases $^{[7-9]}$. Morbidity of PS seems also lower in case of post-PS drainage with a naso-pancreatic drain or a pancreatic stent ${ }^{[6]}$. In case of complete obstruction of the main pancreatic duct in the head, it is sometimes possible to access to the body of the pancreatic duct through the accessory papilla.

\section{Treatment of pancreatic duct strictures by dilatation and stenting}

The procedure consists in setting a 3-4 m length, hydrophilic-top guide wire deep inside the main pancreatic duct to realise a stricture dilatation with balloon or dilatators in order to insert a stent the calibre (5-10 Fr) and length $(3-12 \mathrm{~cm})$ of which depends on pancreatic duct anatomy. The length of the stent is adapted to bridge the stenosis (duct stricture and/or stone); the calibre of the stent depends on the highest calibre of dilatator successfully inserted through the duct stricture. 
In practice, chronic pancreatitis duct strictures are more difficult to pass than biliary stenosis. They are usually associated with an impacted stone which may prevent deep insertion of the guide-wire into the main pancreatic duct. Moreover, pancreatic duct strictures are often narrow and tight because of expanding pancreatic fibrosis. For these reasons, a high rate of failure of dilatation of pancreatic stricture has been reported. Recently, a new technique of dilatation has been reported by Brand $e t a l^{[1]}$. who used a device (Soebendra extractor) previously designed for the extraction of migrated biliary stents. Forage is realised by screwing this instrument through pancreatic duct stenosis on the guidance of a guide-wire. The morbidity rate is low $(0 \%-13 \%)$ because forage is realized in a fibrotic area. Finally, among patients with a stricture which could not be passed with a $7 \mathrm{Fr}$ dilatator, this device $(7 \mathrm{Fr}$ or $10 \mathrm{Fr})$ allowed to pass over the stenosis in all cases ${ }^{[1,10]}$.

Plastic stents are clogged by lithostatine precipates, carbonate of calcium and bio bacterial film in a mean time of four to six $\mathrm{mo}^{[11,12]}$. Therefore, stents have to be retrieved or exchanged every four mo during a variable stenting length of time according to the main series $(2-12 \mathrm{mo})^{[13]}$. Some authors prefer to leave the pancreatic stent and to exchange it only in case of recurrence of symptoms or infection but this strategy is associated with a risk of complications ${ }^{[14]}$. Metallic stent has been proposed because of a longer time of patency but those stents could also be completely obstructed by intra-luminar inflammatory granuloma with a risk of septic complication ${ }^{[15]}$. The morbidity rate of pancreatic stenting is widely varied in series. Early complications (before d 30 after ERCP) are distinct of late complications ( $>30 \mathrm{~d}$ ). The main early complication is acute pancreatitis ( $5 \%-39 \%)$, most of cases are benign, oedematous, spontaneously resolutive forms. A few cases of pancreatic abscess or cholangitis have been reported in the preliminary publications ${ }^{[15,16]}$. Late complications are stent-related: although stent migration is rare $(5 \%)$, stent occlusion is very frequently encountered. Ductal lesions after stenting (dilatation, irregularity, stenosis) have been reported in $21 \%-80 \%$ of cases $^{[17]}$. These lesions are associated with endosonographic parenchymal signs in $68 \%$ of cases $^{[18]}$. In fact, in more than half of the cases, stenting-ductal lesions will regress four mo after retrieval of the stent ${ }^{[17]}$.

\section{Pancreatic stones extraction and lithotripsy}

Pancreatic stones may be retrieved only after a previously PS. Since pancreatic stones are often impacted in the pancreatic duct upstream a duct stenosis, extraction of pancreatic stones is more difficult than extraction of biliary stones. Many difficulties have to be solved before: stenosis above stones have to be dilated, stones have to be fragmented with extracorporeal shock wave lithotripsy (ESWL). After good results obtained for biliary and kidney stones, ESWL has been firstly proposed for pancreatic stones in $1987^{[2]}$. There are three kinds of lithotripter generators: electro magnetic, electro hydraulic and piezoelectric. Stones are visualised under fluoroscopic or ultrasonographic guidance or both, treatment is realized in pro-cubitus position, under general analgesia or sedation.

Results of the major series are reported on Table 1.
Table 1 Results of extracorporeal shock wave lithotripsy

\begin{tabular}{lrcccc}
\hline Authors & $\begin{array}{c}\text { Patients } \\
(\boldsymbol{n})\end{array}$ & $\begin{array}{c}\text { Sessions } \\
(\boldsymbol{n})\end{array}$ & $\begin{array}{c}\text { Symptom } \\
\text { free (\%) }\end{array}$ & $\begin{array}{c}\text { Fragmentation } \\
(\%)\end{array}$ & $\begin{array}{c}\text { Clearance } \\
(\%)\end{array}$ \\
\hline Sauerbruch $^{[19]}$ & 24 & 1.6 & 37 & 87 & 50 \\
Ohara $^{[20]}$ & 32 & 4.6 & 79 & 100 & 75 \\
Costamagna $^{[2]]}$ & 35 & 1.9 & 17 & 100 & 80 \\
Delhaye $^{[22]}$ & 123 & 1.8 & 53 & 99 & 59 \\
Schneider $^{[23]}$ & 50 & 2.4 & 76 & 85 & 56 \\
Total & 264 & $1.6-4.6$ & $17-79$ & $85-100$ & $50-75$ \\
\hline
\end{tabular}

Without ESWL, complete clearance of pancreatic stones was less than $40 \%$. ESWL is successful in $85 \%-100 \%$ of cases and wash-out of stones was obtained in 50\%-75\%. Pain disappeared in $17 \%-79 \%$ of cases $^{[19-23]}$. Morbidity of ESWL is difficult to distinguish from the morbidity related to other endoscopic procedures. Nevertheless, main adverse events of ESWL are abdominal pain and attack of acute pancreatitis. Success factors are more dependant of the site than the size of the stone: juxta-papillary and main pancreatic duct stones are easier to extract than stones located in the tail or in the side branches. Large stones seem easier to break because easier to localize. Duct stenosis is often associated with a pancreatic stone and is a factor of recurrence of pain despite a complete clearance. Fragments of stones are retrieved through PS during a new ERCP, using an extractor-balloon or a Dormia basket; a naso-pancreatic drain is sometimes left to wash the pancreatic ducts during $48 \mathrm{~h}^{[22]}$.

\section{Endoscopic drainage of pancreatic cysts and pseudo- cysts}

Drainage of pancreatic cysts is realised through the stomach wall (gastro-cystostomy) or duodenum wall (duodeno-cystostomy) in case of trans-mural drainage or through the papilla in case of trans-papillary drainage. The trans-mural way is dedicated to bulging cysts into the stomach or duodenum. A diathermic puncture is realized perpendicularly on the site of maximal bulge. After insertion of the catheter deep inside the cyst cavity, a sample of cyst fluid is taken for bacteriologic, biochemical and cytological analysis. A guide-wire is inserted in the cavity in order to realise multiple loops. Then, a careful cystostomy of 5-8 $\mathrm{mm}$ with a papillotome or by balloon dilatation is realised. Large cystostomies appear to be associated with a higher risk of haemorrhage than balloon dilatation. Finally, one or two double-pig-tail stents are inserted. In case of infected cyst or large amount of necrotic tissues which could occlude the stent, a nasocystic drain for washing seems more adapted than a stent.

Trans-papillary drainage is dedicated to communicating cysts. After a selective cannulation of the pancreatic duct, a guide-wire deeply inserted and a pancreatic sphincterotomy, a dilatation of the tract between the pancreatic ducts and the cyst (a down-stream duct stenosis usually being associated), is performed. A stent is inserted into the pancreatic duct in order to bridge the area of communication between the ductal system and the cyst. The mean time of drainage is usually two mo but depends on the persistence of the cyst on the morphologic explorations ${ }^{[24]}$. In case of co-existence of pancreatic duct 
Table 2 Endoscopic treatment of pancreatic duct stenosis

\begin{tabular}{|c|c|c|c|c|c|}
\hline Authors & Patients (n) & Technical Success (\%) & Early improvement of pain (\%) & Follow-up (mo) & $\begin{array}{l}\text { Long-term improvement } \\
\text { of pain }(\%)\end{array}$ \\
\hline Grimm $^{[38]}$ & 70 & 58 & 82 & $2-36$ & 57 \\
\hline Cremer $^{[14]}$ & 76 & 94 & 94 & $18-72$ & 94 \\
\hline Ponchon $^{[39]}$ & 33 & 85 & 74 & 12 & 52 \\
\hline Sauerbruch $^{[40]}$ & 24 & 87 & 83 & 24 & 50 \\
\hline Delhaye $^{[11]}$ & 123 & 95 & 100 & 14 & 37 \\
\hline Schneider ${ }^{[2]}$ & 50 & 86 & 70 & 20 & 70 \\
\hline Binmoller ${ }^{[41]}$ & 93 & & 74 & 58 & 64 \\
\hline Smits $^{[42]}$ & 51 & 96 & 81 & 64 & 24 \\
\hline Dumonceau $^{[43]}$ & 70 & & 95 & 24 & 95 \\
\hline Adame $^{[44]}$ & 80 & & & 40 & 54 \\
\hline Heyries $^{[13]}$ & 70 & 85 & 62 & 29 & 58 \\
\hline $\operatorname{Rösch}^{[45]}$ & 1018 & 70 & - & 59 & 65 \\
\hline Total & 1758 & 85 & 81 & 30 & 61 \\
\hline
\end{tabular}

lesions, a long-term pancreatic stenting is necessary to prevent a recurrence of the cyst.

\section{Endo-ultrasonography}

Interventional endo-ultrasonography (EUS) is particularly interesting in three issues: treatment of pain by coeliac neurolysis, drainage of pseudo cysts and trans-gastric pancreatic drainage. Coeliac block is associated with a low morbidity (diarrhoea in $3.5 \%$ of cases) ${ }^{[25,26]}$. Treatment of pancreatic cysts under EUS guidance is dedicated for pseudo cysts which are not bulging in the gut ${ }^{[27-32]}$. In case of complete obstruction of the pancreatic duct, a pancreatico-gastrostomy can be achieved under EUS guidance ${ }^{[33,34]}$.

\section{RESULTS AND INDICATIONS OF ENDOSCOPIC TREATMENT}

The aim of endoscopic treatment is improvement of pain. Analysis of the literature is difficult because (a) the variability of pain during the time and between patients ${ }^{[35-37]}$ (b) the pain during CP is multifactorial: ductal or interstitial pancreatic hyperpression, inflammatory infiltration of peri pancreatic nerves ("pancreatic neuritis") or pseudo-cysts. Other complications of CP could also be associated with pain: duodenal stenosis, duodenal cystic dystrophy, biliary stenosis or duodenal ulcer ${ }^{[35]}$. Moreover, endoscopic methods are different: biliary sphincterotomy is not always associated with a pancreatic sphincterotomy, time of pancreatic stenting (two months to undetermined), or number of stents. In fact, there are several methods of treatment which aim to obtain a satisfactory drainage of a pancreatic and/or biliary duct.

\section{Treatment of pancreatic pain}

Drainage of pancreatic duct is reported in numerous articles $^{[11,13,14,23,38-45]}$. Technical success was obtained in $85 \%$ of cases (58\%-96\%). Stents are left during variable length of time, from two mo to endless. Short-term improvement of pain was obtained in $81 \%$ of cases $(62 \%-100 \%)$. After a follow-up of $30 \mathrm{mo}$ (14-60 mo), improvement of pain dropped to $61 \%$ of cases $(24 \%-95 \%)$. There was no clinical predictive factor of success despite of an early stage of CP reported in three series ${ }^{[13,41,43]}$. Communicating cyst and juxta-ampullary stenosis were the two reported morphological predictive factor of success. Surprisingly, stop of alcohol intake did not seem to modify results of the endoscopic treatment. Nevertheless, alcohol intake has to be stopped because morbidity and mortality of CP are more attributed to toxic habits (alcohol or tobacco) than to CP itself ${ }^{[4]}$. In cases of complete obstruction of pancreatic duct preventing access via the papilla, EUSguided pancreatico-gastrostomy can be done. Results of this method are preliminary: a short series of four cases has reported good results in one case, recurrence of pain in two cases managed with another endoscopic treatment (stenosis of the pancreatico-gastrostomy in one case, disruption and spontaneous migration of the stent in the other case), and failure in one case (12 mo of follow-up) ${ }^{[33]}$. An additional factor of pain is peripancreatic inflammatory infiltrate of nerves: a prospective randomized comparison of endoscopic ultrasound and computed tomography-guided celiac plexus block has reported better results under EUS whereby an immediate improvement of pain occurred in $50 \%$ of cases but this result dropped to $30 \%$ after six months of follow-up. Efficiency appeared significantly more prolonged in the EUS-group and the ratio cost-efficiency was also better in this group ${ }^{[47]}$. More recently, a prospective study including 90 patients reported an immediate improvement of pain in $55 \%$ and in $10 \%$ after six months of follow-up ${ }^{[25]}$. Young age or previously pancreatic surgery were factors of poor results. Indication of celiac plexus block is limited in CP because of a relative immediate efficiency and especially a frequently recurrence of pain after six mo of follow-up (Table 2).

\section{Treatment of pancreatic cysts and pseudo cysts}

Evaluation of patient and collection are the first step to decide strategic therapy. Ultrasonography, computedtomography, MRCP and EUS make it possible for clinician to determine the two major risks of endoscopic treatment which are haemorrhage and perforation. Haemorrhage depends on the presence of pericystic or peridigestive vessels, segmental portal hypertension and the haemorrhagic content of the cyst. Perforation depends on the distance between the digestive-wall and 
Table 3 Results of endoscopic cysto-enterostomy during chronic pancreatitis

\begin{tabular}{|c|c|c|c|c|c|c|c|}
\hline Authors & Cysto-gastrost & Cysto-duodenost & Failure $(n)$ & Recurrence $(n)$ & Secondarysurgery & Morbidity $(n)$ & Mortality (n) \\
\hline Dohmoto $^{[48]}$ & 5 & 1 & 0 & - & 1 & 0 & 0 \\
\hline Cremer $^{[49]}$ & 11 & 22 & 1 & 3 & 5 & 3 & 0 \\
\hline Bejanin $^{[50]}$ & 9 & 5 & 2 & 3 & 6 & 3 & 0 \\
\hline Barthet ${ }^{[51]}$ & 12 & 66 & 0 & 14 & 2 & 12 & 1 \\
\hline Smits ${ }^{[52]}$ & 16 & 10 & 3 & 3 & 8 & 5 & 0 \\
\hline Binmoeller ${ }^{[53]}$ & \multicolumn{2}{|c|}{24} & 4 & 6 & 5 & 5 & 0 \\
\hline Total & \multicolumn{2}{|c|}{181} & $10(5.5 \%)$ & $29(16 \%)$ & $27(15 \%)$ & $28(15.5 \%)$ & $1(0.5 \%)$ \\
\hline
\end{tabular}

Table 4 Results of endoscopic transpapillary drainage of pancreatic cysts

\begin{tabular}{|c|c|c|c|c|c|c|}
\hline Authors & Patients (n) & Stent $(\mathrm{Fr})$ & Healing $(n)$ & Recurrence $(n)$ & Morbidity (n) & Secondary surgery $(n)$ \\
\hline Kozarek $^{[55]}$ & 8 & - & 7 & 0 & 3 & 4 \\
\hline Dohmoto $^{[48]}$ & 6 & 7 & 6 & 1 & 2 & 0 \\
\hline${ }^{1}$ Barthet ${ }^{[56]}$ & 30 & $7-10$ & 23 & 3 & 4 & 5 \\
\hline${ }^{2} \mathrm{Smits}^{[52]}$ & 19 & $7-10$ & 14 & - & 1 & - \\
\hline Binmoeller ${ }^{[53]}$ & 37 & $5-7$ & 35 & 5 & 1 & - \\
\hline Catalano $^{[57]}$ & 21 & $5-10$ & 17 & 1 & 1 & 2 \\
\hline Total $(n)$ & 121 & $7 \mathrm{Fr}$ & $102(85 \%)$ & $10(9.8 \%)$ & $12(10 \%)$ & $11(11 \%)$ \\
\hline
\end{tabular}

${ }^{1}$ transpapillary drainage + cysto-gastrostomy $(n=5) ;+$ cysto-duodenostomy $(n=5) ;{ }^{2}$ transpapillary drainage + cysto-gastrostomy $(n=4) ;+$ cysto-duodenostomy $(n=2) ;+$ cysto-gastrostomy and cysto-duodenostomy $(n=1)$.

the cyst which should not exceed $10 \mathrm{~mm}$. Results of transmural drainage were reported in six series between 1989 and 1992 including 191 cysts (Table 3) ${ }^{[48-53]}$. Mean rate of healing, failure and recurrence were respectively $78 \%(51 \%-82 \%), 5.5 \%(0 \%-16 \%)$ and $6.5 \%(3 \%-13 \%)$. Secondary surgical procedure was necessary in $14.9 \%$ of patients $(12 \%-30 \%)$. Morbidity was $15.5 \%$ including, according to increasing rates of frequency, haemorrhage, perforation, and infection. Haemorrhage seems more frequent in case of gastro-cystostomy than for duodenocystostomy $^{[51]}$. The only death reported concerned a patient who presented cirrhosis complicated by portal hypertension and associated with haemorrhagic pancreatic ascitis $^{[51]}$. Long-term results of transmural drainage are not well-known, follow-up not exceeding 31 mo. A recent study including 34 patients followed $46 \mathrm{mo}$, reported good results in $62 \%$ of cases (in intent to treat) with only $71 \%$ of initially technical success ${ }^{[54]}$. Three cases of recurrence were reported, of whom two cases were successfully managed endoscopically.

Results of trans-papillary drainage have been also reported in six series from 1991 to 1995 including 121 cysts (Table 4$)^{[48,53,55-57]}$. Symptom-free rates were $87 \%(76 \%-87 \%)$ and healing rates of cysts were $84 \%$ (76\%-94\%). Recurrence of cyst was $9.2 \%$, morbidity was $10 \%$ with essentially septic complications and postERCP acute pancreatitis. A secondary surgical procedure was necessary in $10.8 \%$ of cases ( $9 \%-50 \%)$. Endoscopic drainage is intended for symptomatic cysts. In the other cases, drainage is necessary if the size of the cyst is more than $4 \mathrm{~cm}$, particularly if the cyst is localized out of pancreatic area because, in this case, it uncommonly collapses spontaneously ${ }^{[58]}$. Trans-papillary drainage appears a first choice treatment in case of CP because pancreatic stent treats also pancreatic ductal lesions down stream the cyst and because it is less invasive than transmural way. Transmural drainage is especially reserved to large cysts but must be avoided in presence of segmental portal hypertension. Results of EUS-guided pseudo-cysts drainage have been recently reported in six series including 69 cases $^{[27-32]}$. The most important monocentric study included 35 patients of whom 20 pancreatic abscess: after 27 mo of follow-up, drainage was successful in $94 \%$ of cases, a pneuperitoneum occurred in a case and has been managed conservatively, recurrence of cyst occurred in three cases of whom two abscess, surgical drainage was necessary in four cases of whom were four abscess. This method seems satisfying but has to be more evaluated in larger series ${ }^{[31]}$.

\section{Endoscopic treatment of biliary stenosis}

Long-term results of biliary stenting have been reported in three series including 102 patients $^{[59-61]}$. Although initial improvement was reported in $100 \%$ of cases, the rate of symptom free patients decreased to $17.5 \%(10 \%-28 \%)$ after 10 mo (14-49 mo) of follow-up; moreover, 68\% of patients underwent a surgical bili-digestive diversion or were still stenting. Plastic stents temporarily improve cholestasis but are not able to dilate adequately common bile duct. In contrast with the previous series, a recent study including 25 patients using balloon dilatation before biliary stenting has reported excellent results in $80 \%$ of cases after 13 mo of follow-up ${ }^{[62]}$. These recent optimistic results attributed to the balloon dilatation, have to be confirmed. Morbidity is low (8\%-9\%) except migration or obstruction of the stent observed in respectively 14/25 and 18/25 patients of series of Deviere et al and Vitale et al ${ }^{[59,62]}$. Draganov et al tried to improve results by using several stents: nine patients underwent a biliary stenting with $2-(n=3)$ or 3- $(n=6) 10$ French-stent; 48 mo after 
Table 5 Results of endoscopic biliary stenting of biliary stenosis associated with chronic pancreatititis

\begin{tabular}{|c|c|c|c|c|c|c|}
\hline Authors & Patients $(n)$ & Clinical improvement (\%) & Stent obstruction (\%) & Stent migration (\%) & Healing (\%) & Length of time of stenting (mo) \\
\hline Devière ${ }^{[59]}$ & 25 & 100 & 32 & 40 & 12 & - \\
\hline Barthet ${ }^{[6]}$ & 19 & 100 & 0 & 5 & 10.5 & 10 \\
\hline Smits ${ }^{[6]]}$ & 58 & 100 & 62 & 7 & 27 & 10 \\
\hline Vitale $^{[62]}$ & 25 & 100 & & & 80 & 13 \\
\hline
\end{tabular}

retrieval of stents, biliary stenosis recurred in only $55 \%$ of cases, absence of cephalic pancreatic stones was a factor of success ${ }^{[63]}$. Because plastic stent are not adapted for a long-term drainage, Deviere et al tested metallic expansive stent with an excellent result in 18/20 patients, after 33 mo of follow-up ${ }^{[64]}$. Nevertheless, the two remaining patients presented an obstruction of the stent secondary to epithelial hyperplasia in contact with the stent. More recently, a study including 13 patients presenting a biliary stenosis and unfit for surgical procedure, reported good results in $9 / 13(69 \%)$ patients after 50 mo of follow-up, mean time of stent patency was $60 \mathrm{mo}^{[65]}$. A single stent was enough in five cases, obstruction of the stent was managed by insertion of a plastic stent inside the metallic stent $(n=3)$ or by an extractor balloon $(n=1)$. In four $(21 \%)$ cases, biliary drainage was not effective because of occluded stent $(n=3)$ or duodenal migration of the stent $(n=1)$. Three patients died for a cause not related to the biliary stenosis. Nevertheless, those metallic stents being not extractable, after a long-term follow-up, there is a possibility of stent occlusion by granulation reaction against a foreign body (Table 5).

\section{Management of pancreatic exocrine and endocrine functions}

Although improvement of pancreatic exocrine and endocrine functions is frequently discussed in surgical series, this notion is seldom reported in endoscopic series $^{[13,22]}$. This is probably due to the difficulties to correctly explore the pancreatic exocrine function and also to the relatively short-term follow-up of endoscopic series in compared with surgical series. A temporary improvement of diabetes mellitus has been reported in $10 \%$ of cases after endoscopic treatment, while aggravation was noted in $12 \%{ }^{[22]}$. Although another series reported an improvement in $26 \%$ of cases $^{[13]}$, most of the series did not noted any improvement ${ }^{[42,44]}$. Therefore, diabetes mellitus alone should not be an indication of endoscopic treatment of CP.

Evaluation of the effects of endoscopic treatment on pancreatic exocrine function is also seldom precise. A few studies report a gain of weight but this gain probably reflects more improvement of pain than improvement of exocrine function ${ }^{[13]}$. Evaluation of pancreatic exocrine function with a $\mathrm{C}^{14}$ breath test reports a $50 \%-60 \%$ improvement after endoscopic treatment ${ }^{[22]}$.

\section{Endoscopic treatment of pancreatic fistulas}

Three major series included 39 patients presenting with a pancreatic fistula after acute pancreatitis $(n=19)$ and associated with CP $(n=12)^{[55,66,67]}$. Treatment consisted in a trans-papillary drainage of pancreatic duct in 34 cases, associated with a transmural drainage of a cyst in four cases. Rate of success was $92 \%$, with complications occurring in seven cases (17\%). Complications included mainly acute pancreatitis and sepsis. Seven (17\%) patients underwent surgical procedures 11 to 16 mo after endoscopic treatment. Few isolated cases of pancreaticopleural fistula successful treated by endoscopic drainage, have been reported ${ }^{[68]}$. Trans-papillary drainage is also reported as a successful treatment for pancreaticoperitoneal fistulas.

\section{ENDOSCOPIC TREATMENT AND SURGICAL PROCEDURES}

Up to now, few randomised series have covered this topic. A recent study concludes in favour of surgery ${ }^{[09]}$. This study randomized 72 patients and after a followup of five years, although incomplete improvement of pain was equivalent in the two groups $(46 \%$ versus $52 \%$ ), a significant difference appeared for the complete resolution of pain (37\% in the surgical group versus $14 \%$ in the endoscopic group). Nevertheless this series presents a bias because $80 \%$ of patients in the surgical group underwent a resection procedure and only $20 \%$ underwent a derivation procedure. Therefore, results of endoscopic treatment have to be compared with surgical procedure of derivation. Moreover, half of patients accepted randomization between surgery and endoscopy, this high rate of refusal emphasizes the difficulties in comparing the two methods and to set-up this kind of study. Nevertheless, more recently, another prospective series reported that surgical drainage of the pancreatic duct was more effective than endoscopic treatment ${ }^{[70]}$. Thirty-nine symptomatic patients having $\mathrm{CP}$ with distal obstruction of the main pancreatic duct and without inflammatory mass were randomized: 19 underwent endoscopic trans-papillary drainage (16 of whom also underwent ESWL) and 20 had operative pancreaticojejunostomy. After 24 mo of follow-up, patients who underwent surgery had a significant $(P<0.001)$ lower pain score compared to endoscopic drainage. Moreover, complete or partial pain relief was achieved in $75 \%$ of patients of "surgical group" and only $36 \%$ of patients of "endoscopic group" $(P=0.007)$. Morbidity rate and length of hospital stay were similar in the two groups but there were more procedures in the "endoscopic group" than in "surgical group" (a median of $8 v$ s). To conclude, strategy depends on the expertise of the local teams, endoscopic treatment could be proposed as a first line treatment, before surgical procedure. 


\section{CONCLUSION}

Endoscopic treatment of CP has certainly improved during the last two decades. Although results are clearly accepted as excellent for pancreatic cysts and pancreatic fistulas, long-term improvement of biliary and pancreatic ducts stenosis remains controversial.

\section{REFERENCES}

1 Brand B, Thonke F, Obytz S, Binmoeller KF, Rathod V, Seitz U, Bohnacker S, Jäckle S, Soehendra N. Stent retriever for dilation of pancreatic and bile duct strictures. Endoscopy 1999; 31: 142-145

2 Sauerbruch T, Holl J, Sackmann M, Werner R, Wotzka R, Paumgartner G. Disintegration of a pancreatic duct stone with extracorporeal shock waves in a patient with chronic pancreatitis. Endoscopy 1987; 19: 207-208

3 Fuji T, Amano H, Harima K, Aibe T, Asagami F, Kinukawa K, Ariyama S, Takemoto T. Pancreatic sphincterotomy and pancreatic endoprosthesis. Endoscopy 1985; 17: 69-72

4 Sherman S, Lehman GA. Endoscopic pancreatic sphincterotomy: techniques and complications. Gastrointest Endosc Clin N Am 1998; 8: 115-124

5 Kim MH, Myung SJ, Kim YS, Kim HJ, Seo DW, Nam SW, Ahn JH, Lee SK, Min YI. Routine biliary sphincterotomy may not be indispensable for endoscopic pancreatic sphincterotomy. Endoscopy 1998; 30: 697-701

6 Elton E, Howell DA, Parsons WG, Qaseem T, Hanson BL. Endoscopic pancreatic sphincterotomy: indications, outcome, and a safe stentless technique. Gastrointest Endosc 1998; 47: 240-249

7 Rabenstein T, Schneider HT, Bulling D, Nicklas M, Katalinic A, Hahn EG, Martus P, Ell C. Analysis of the risk factors associated with endoscopic sphincterotomy techniques: preliminary results of a prospective study, with emphasis on the reduced risk of acute pancreatitis with low-dose anticoagulation treatment. Endoscopy 2000; 32: 10-19

8 Freeman ML, Nelson DB, Sherman S, Haber GB, Herman ME, Dorsher PJ, Moore JP, Fennerty MB, Ryan ME, Shaw MJ, Lande JD, Pheley AM. Complications of endoscopic biliary sphincterotomy. N Engl J Med 1996; 335: 909-918

9 Loperfido S, Angelini G, Benedetti G, Chilovi F, Costan F, De Berardinis F, De Bernardin M, Ederle A, Fina P, Fratton A. Major early complications from diagnostic and therapeutic ERCP: a prospective multicenter study. Gastrointest Endosc 1998; 48: $1-10$

10 Ziebert JJ, DiSario JA. Dilation of refractory pancreatic duct strictures: the turn of the screw. Gastrointest Endosc 1999; 49: 632-635

11 Provansal-Cheylan M, Bernard JP, Mariani A, Soehendra N, Cremer M, Sahel J, Sarles H. Occluded pancreatic endoprostheses--analysis of the clogging material. Endoscopy 1989; 21: 63-69

12 Smits ME, Groen AK, Mok KS, van Marle J, Tytgat GN, Huibregtse K. Analysis of occluded pancreatic stents and juices in patients with chronic pancreatitis. Gastrointest Endosc 1997; 45: 52-58

13 Heyries L, Barthet M, Miranda C, Bernard JP, Sahel J. Pancreatic intubation by endoscopy in chronic calcifying pancreatitis. Gastroenterol Clin Biol 1999; 23: 469-476

14 Cremer M, Devière J, Delhaye M, Baize M, Vandermeeren A. Stenting in severe chronic pancreatitis: results of medium-term follow-up in seventy-six patients. Endoscopy 1991; 23: 171-176

15 Eisendrath $\mathbf{P}$, Devière J. Expandable metal stents for benign pancreatic duct obstruction. Gastrointest Endosc Clin N Am 1999; 9: 547-554

16 Siegel J, Veerappan A. Endoscopic management of pancreatic disorders: potential risks of pancreatic prostheses. Endoscopy 1991; 23: 177-180

17 Smith MT, Sherman S, Ikenberry SO, Hawes RH, Lehman GA. Alterations in pancreatic ductal morphology following polyethylene pancreatic stent therapy. Gastrointest Endosc 1996; 44: 268-275

18 Sherman S, Hawes RH, Savides TJ, Gress FG, Ikenberry SO, Smith MT, Zaidi S, Lehman GA. Stent-induced pancreatic ductal and parenchymal changes: correlation of endoscopic ultrasound with ERCP. Gastrointest Endosc 1996; 44: 276-282

19 Sauerbruch T, Holl J, Sackmann M, Paumgartner G. Extracorporeal lithotripsy of pancreatic stones in patients with chronic pancreatitis and pain: a prospective follow up study. Gut 1992; 33: 969-972

20 Ohara H, Hoshino M, Hayakawa T, Kamiya Y, Miyaji M, Takeuchi T, Okayama Y, Gotoh K. Single application extracorporeal shock wave lithotripsy is the first choice for patients with pancreatic duct stones. Am J Gastroenterol 1996; 91: 1388-1394

21 Costamagna G, Gabbrielli A, Mutignani M, Perri V, Pandolfi M, Boscaini M, Crucitti F. Extracorporeal shock wave lithotripsy of pancreatic stones in chronic pancreatitis: immediate and medium-term results. Gastrointest Endosc 1997; 46: 231-236

22 Delhaye $\mathbf{M}$, Vandermeeren A, Baize $\mathbf{M}$, Cremer $\mathbf{M}$. Extracorporeal shock-wave lithotripsy of pancreatic calculi. Gastroenterology 1992; 102: 610-620

23 Schneider HT, May A, Benninger J, Rabenstein T, Hahn EG, Katalinic A, Ell C. Piezoelectric shock wave lithotripsy of pancreatic duct stones. Am J Gastroenterol 1994; 89: 2042-2048

24 Arvanitakis M, Delhaye M, Bali MA, Matos C, De Maertelaer V, Le Moine $O$, Devière J. Pancreatic-fluid collections: a randomized controlled trial regarding stent removal after endoscopic transmural drainage. Gastrointest Endosc 2007; 65: 609-619

25 Gress F, Schmitt C, Sherman S, Ciaccia D, Ikenberry S, Lehman G. Endoscopic ultrasound-guided celiac plexus block for managing abdominal pain associated with chronic pancreatitis: a prospective single center experience. Am J Gastroenterol 2001; 96: 409-416

26 Wiersema MJ, Wiersema LM. Endosonography-guided celiac plexus neurolysis. Gastrointest Endosc 1996; 44: 656-662

27 Giovannini M, Bernardini D, Seitz JF. Cystogastrotomy entirely performed under endosonography guidance for pancreatic pseudocyst: results in six patients. Gastrointest Endosc 1998; 48: 200-203

28 Seifert H, Dietrich C, Schmitt T, Caspary W, Wehrmann T. Endoscopic ultrasound-guided one-step transmural drainage of cystic abdominal lesions with a large-channel echo endoscope. Endoscopy 2000; 32: 255-259

29 Fuchs M, Reimann FM, Gaebel C, Ludwig D, Stange EF. Treatment of infected pancreatic pseudocysts by endoscopic ultrasonography-guided cystogastrostomy. Endoscopy 2000; 32: 654-657

30 Vilmann P, Hancke S, Pless T, Schell-Hincke JD, Henriksen FW. One-step endosonography-guided drainage of a pancreatic pseudocyst: a new technique of stent delivery through the echo endoscope. Endoscopy 1998; 30: 730-733

31 Giovannini M, Pesenti C, Rolland AL, Moutardier V, Delpero JR. Endoscopic ultrasound-guided drainage of pancreatic pseudocysts or pancreatic abscesses using a therapeutic echo endoscope. Endoscopy 2001; 33: 473-477

32 Sanchez Cortes E, Maalak A, Le Moine O, Baize M, Delhaye M, Matos C, Devière J. Endoscopic cystenterostomy of nonbulging pancreatic fluid collections. Gastrointest Endosc 2002; 56: 380-386

33 François E, Kahaleh M, Giovannini M, Matos C, Devière J. EUS-guided pancreaticogastrostomy. Gastrointest Endosc 2002; 56: 128-133

34 Giovannini M. What is the best endoscopic treatment for pancreatic pseudocysts? Gastrointest Endosc 2007; 65: 620-623

35 Lévy P, Ruszniewski P, Bernades P. Natural history of chronic alcoholic pancreatitis. Gastroenterol Clin Biol 2000; 24: 725-741

36 Ammann RW, Muellhaupt B. Progression of alcoholic acute to chronic pancreatitis. Gut 1994; 35: 552-556

37 Lankisch PG, Löhr-Happe A, Otto J, Creutzfeldt W. Natural course in chronic pancreatitis. Pain, exocrine and endocrine pancreatic insufficiency and prognosis of the disease. Digestion 


\section{3; 54: 148-155}

38 Grimm H, Meyer WH, Nam VC, Soehendra N. New modalities for treating chronic pancreatitis. Endoscopy 1989; 21: 70-74

39 Ponchon T, Bory RM, Hedelius F, Roubein LD, Paliard P, Napoleon B, Chavaillon A. Endoscopic stenting for pain relief in chronic pancreatitis: results of a standardized protocol. Gastrointest Endosc 1995; 42: 452-456

40 Sauerbruch T, Holl J, Sackmann M, Paumgartner G. Extracorporeal shock wave lithotripsy of pancreatic stones. Gut 1989; 30: 1406-1411

41 Binmoeller KF, Jue P, Seifert H, Nam WC, Izbicki J, Soehendra $\mathrm{N}$. Endoscopic pancreatic stent drainage in chronic pancreatitis and a dominant stricture: long-term results. Endoscopy 1995; 27: 638-644

42 Smits ME, Badiga SM, Rauws EA, Tytgat GN, Huibregtse K. Long-term results of pancreatic stents in chronic pancreatitis. Gastrointest Endosc 1995; 42: 461-467

43 Dumonceau JM, Devière J, Le Moine O, Delhaye M, Vandermeeren A, Baize M, Van Gansbeke D, Cremer M. Endoscopic pancreatic drainage in chronic pancreatitis associated with ductal stones: long-term results. Gastrointest Endosc 1996; 43: 547-555

44 Adamek HE, Jakobs R, Buttmann A, Adamek MU, Schneider AR, Riemann JF. Long term follow up of patients with chronic pancreatitis and pancreatic stones treated with extracorporeal shock wave lithotripsy. Gut 1999; 45: 402-405

45 Rösch T, Daniel S, Scholz M, Huibregtse K, Smits M, Schneider T, Ell C, Haber G, Riemann JF, Jakobs R, Hintze R, Adler A, Neuhaus H, Zavoral M, Zavada F, Schusdziarra V, Soehendra N. Endoscopic treatment of chronic pancreatitis: a multicenter study of 1000 patients with long-term follow-up. Endoscopy 2002; 34: 765-771

46 Lowenfels AB, Maisonneuve P, Cavallini G, Ammann RW, Lankisch PG, Andersen JR, DiMagno EP, Andrén-Sandberg A, Domellöf L, Di Francesco V. Prognosis of chronic pancreatitis: an international multicenter study. International Pancreatitis Study Group. Am J Gastroenterol 1994; 89: 1467-1471

47 Gress F, Schmitt C, Sherman S, Ikenberry S, Lehman G. A prospective randomized comparison of endoscopic ultrasound- and computed tomography-guided celiac plexus block for managing chronic pancreatitis pain. Am J Gastroenterol 1999; 94: 900-905

48 Dohmoto M, Rupp KD. Endoscopic drainage of pancreatic pseudocysts. Surg Endosc 1992; 6: 118-124

49 Cremer M, Deviere J, Engelholm L. Endoscopic management of cysts and pseudocysts in chronic pancreatitis: long-term followup after 7 years of experience. Gastrointest Endosc 1989; 35: 1-9

50 Béjanin H, Liguory C, Ink O, Fritsch J, Choury AD, Lefebvre JF, Vilgrain V, Etienne JP. Endoscopic drainage of pseudocysts of the pancreas. Study of 26 cases. Gastroenterol Clin Biol 1993; 17: $804-810$

51 Barthet M, Bugallo M, Moreira LS, Bastid C, Sastre B, Sahel J. Management of cysts and pseudocysts complicating chronic pancreatitis. A retrospective study of 143 patients. Gastroenterol Clin Biol 1993; 17: 270-276

52 Smits ME, Rauws EA, Tytgat GN, Huibregtse K. The efficacy of endoscopic treatment of pancreatic pseudocysts. Gastrointest Endosc 1995; 42: 202-207

53 Binmoeller KF, Seifert H, Walter A, Soehendra N. Transpapillary and transmural drainage of pancreatic pseudocysts. Gastrointest Endosc 1995; 42: 219-224
54 Beckingham IJ, Krige JE, Bornman PC, Terblanche J. Long term outcome of endoscopic drainage of pancreatic pseudocysts. Am J Gastroenterol 1999; 94: 71-74

55 Kozarek RA, Ball TJ, Patterson DJ, Freeny PC, Ryan JA, Traverso LW. Endoscopic transpapillary therapy for disrupted pancreatic duct and peripancreatic fluid collections. Gastroenterology 1991; 100: 1362-1370

56 Barthet M, Sahel J, Bodiou-Bertei C, Bernard JP. Endoscopic transpapillary drainage of pancreatic pseudocysts. Gastrointest Endosc 1995; 42: 208-213

57 Catalano MF, Geenen JE, Schmalz MJ, Johnson GK, Dean RS, Hogan WJ. Treatment of pancreatic pseudocysts with ductal communication by transpapillary pancreatic duct endoprosthesis. Gastrointest Endosc 1995; 42: 214-218

58 Gouyon B, Lévy P, Ruszniewski P, Zins M, Hammel P, Vilgrain V, Sauvanet A, Belghiti J, Bernades P. Predictive factors in the outcome of pseudocysts complicating alcoholic chronic pancreatitis. Gut 1997; 41: 821-825

59 Devière J, Devaere S, Baize M, Cremer M. Endoscopic biliary drainage in chronic pancreatitis. Gastrointest Endosc 1990; 36 96-100

60 Barthet M, Bernard JP, Duval JL, Affriat C, Sahel J. Biliary stenting in benign biliary stenosis complicating chronic calcifying pancreatitis. Endoscopy 1994; 26: 569-572

61 Smits ME, Rauws EA, van Gulik TM, Gouma DJ, Tytgat GN, Huibregtse K. Long-term results of endoscopic stenting and surgical drainage for biliary stricture due to chronic pancreatitis. Br J Surg 1996; 83: 764-768

62 Vitale GC, Reed DN Jr, Nguyen CT, Lawhon JC, Larson GM. Endoscopic treatment of distal bile duct stricture from chronic pancreatitis. Surg Endosc 2000; 14: 227-231

63 Draganov P, Hoffman B, Marsh W, Cotton P, Cunningham J. Long-term outcome in patients with benign biliary strictures treated endoscopically with multiple stents. Gastrointest Endosc 2002; 55: 680-686

64 Deviere J, Cremer M, Baize M, Love J, Sugai B, Vandermeeren A. Management of common bile duct stricture caused by chronic pancreatitis with metal mesh self expandable stents. Gut 1994; 35: 122-126

65 van Berkel AM, Cahen DL, van Westerloo DJ, Rauws EA, Huibregtse K, Bruno MJ. Self-expanding metal stents in benign biliary strictures due to chronic pancreatitis. Endoscopy 2004; 36: 381-384

66 Devière J, Bueso H, Baize M, Azar C, Love J, Moreno E, Cremer M. Complete disruption of the main pancreatic duct: endoscopic management. Gastrointest Endosc 1995; 42: 445-451

67 Bracher GA, Manocha AP, DeBanto JR, Gates LK Jr, Slivka A, Whitcomb DC, Bleau BL, Ulrich CD 2nd, Martin SP. Endoscopic pancreatic duct stenting to treat pancreatic ascites. Gastrointest Endosc 1999; 49: 710-715

68 Hastier P, Rouquier P, Buckley M, Simler JM, Dumas R, Delmont JP. Endoscopic treatment of wirsungo-cysto-pleural fistula. Eur J Gastroenterol Hepatol 1998; 10: 527-529

69 Díte P, Ruzicka M, Zboril V, Novotný I. A prospective, randomized trial comparing endoscopic and surgical therapy for chronic pancreatitis. Endoscopy 2003; 35: 553-558

70 Cahen DL, Gouma DJ, Nio Y, Rauws EA, Boermeester MA, Busch OR, Stoker J, Laméris JS, Dijkgraaf MG, Huibregtse K, Bruno MJ. Endoscopic versus surgical drainage of the pancreatic duct in chronic pancreatitis. N Engl J Med 2007; 356: 676-684

S- Editor Liu Y L- Editor Roberts SE E- Editor Yin DH 